\title{
Preparation and Its Adsorptive Property of Modified Expanded Graphite Nanomaterials
}

\author{
Liqin Wang, ${ }^{1,2}$ Xiujun Fu, ${ }^{1}$ E. Chang, ${ }^{1}$ Haitao Wu, ${ }^{1}$ Kun Zhang, Xianchao Lei, \\ Ruijun Zhang, ${ }^{2}$ Xiaowen Qi, ${ }^{3}$ and Yulin Yang ${ }^{3}$ \\ ${ }^{1}$ Hebei Key Laboratory of Applied Chemistry, College of Environmental and Chemical Engineering, Yanshan University, \\ Qinhuangdao 066004, China \\ ${ }^{2}$ State Key Laboratory of Metastable Materials Science and Technology, Yanshan University, Qinhuangdao 066004, China \\ ${ }^{3}$ College of Mechanical Engineering, Yanshan University, Qinhuangdao, Hebei 066004, China
}

Correspondence should be addressed to Liqin Wang; wangliqin@ysu.edu.cn

Received 6 November 2013; Revised 8 January 2014; Accepted 9 January 2014; Published 12 February 2014

Academic Editor: Lavinia Balan

Copyright (C) 2014 Liqin Wang et al. This is an open access article distributed under the Creative Commons Attribution License, which permits unrestricted use, distribution, and reproduction in any medium, provided the original work is properly cited.

\begin{abstract}
Modified expanded graphite (MEG) samples were prepared by strong acid treatment modification. As-prepared MEG samples were characterized by the means of FE-SEM, XRD, FT-IR, $\mathrm{N}_{2}$ physical adsorption measurements, and TG-DTA. The influences of expanded volume and oil viscosity on adsorptive property of MEG samples were investigated. The results suggest that MEG samples have high crystallinity. The pores of MEG samples can be divided into three levels from FE-SEM images. All of the functional groups of MEG samples are nonpolar. The expansion temperature of modified expansible graphite starts at about $700^{\circ} \mathrm{C}$. The sorption capacity of MEG increases gradually with expanded volume and oil viscosity increase. When the expanded volume of MEG samples is $320 \mathrm{~mL} / \mathrm{g}$, its maximum sorption capacity is up to $84.681 \mathrm{~g} / \mathrm{g}$ for gear oil with the highest viscosity.
\end{abstract}

\section{Introduction}

In recent years, the spill oils pollutions have caused extensive and widespread concerns. Spill oils not only severely pollute the marine environment but also threaten the human lives. The expanded graphite (EG) with a majority of macropores [1-3] and nonpolar surface make it as an excellent material for absorbing nonpolar and macromolecular compounds, especially for various kinds of oils. EG has been usually prepared through the sequential intercalating, washing, drying, and puffing from the natural flake graphite $[4,5]$. Many scholars have paid more attention to research the relationships between the preparation conditions, pore structure, and its sorption capacities [6-8]. Furthermore, EG has also been widely applied in waste gas removal [9], catalysts carrier [1012], medical materials [13], and many other fields [14-16]. However, EG has some disadvantages such as fragile, light mass and low expanded ratio by one step processing, so that a lot of studies have been focused on its modification researches [17-25]. The modification methods for EG mainly include strong acid treatment modification, in-situ modification, surfactant modification, and surface coating modification $[26,27]$.

In this paper, $\mathrm{H}_{2} \mathrm{O}_{2}$ was used as the oxidant, concentrated $\mathrm{H}_{2} \mathrm{SO}_{4}$ was used as the intercalator, and the MEG samples were prepared by strong acid treatment modification. The MEG samples were characterized by FE-SEM, XRD, FT-IR, $\mathrm{N}_{2}$ physical adsorption measurements, and TG-DTA. Six kinds of industrial oils such as gasoline, kerosene, diesel oil, machine oil, crude oil, and gear oil were used as sorbents to investigate the sorption capacity of MEG samples.

\section{Experimental}

2.1. Materials. 3599-flake graphite, concentrated $\mathrm{H}_{2} \mathrm{SO}_{4}$ (98 wt.\%), $\mathrm{H}_{2} \mathrm{O}_{2}$ solution (30 wt.\%), distilled water, gasoline, kerosene, diesel oil, machine oil, crude oil, and gear oil were used.

2.2. Preparation. Weighed $2 \mathrm{~g}$ of expansible graphite was put into a beaker, and then it was mixed with concentrated $\mathrm{H}_{2} \mathrm{SO}_{4}$ 


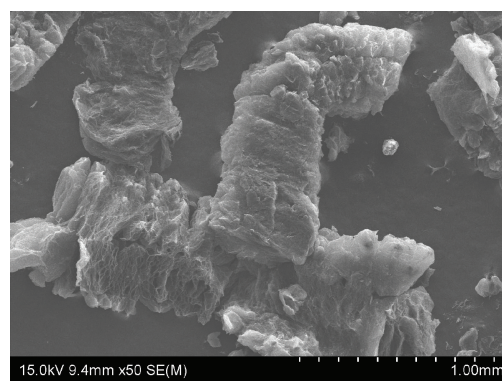

(a)

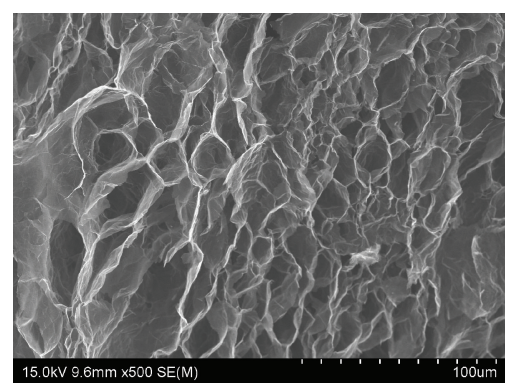

(b)

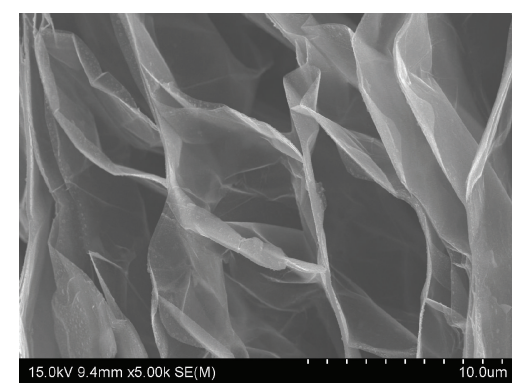

(c)

Figure 1: FE-SEM images of the MEG samples.

and $\mathrm{H}_{2} \mathrm{O}_{2}$ solution (volume ratio $10: 1.5$ ) and was stirred with them until it formed an even mixture. Then, the beaker was put in the water bath at $45^{\circ} \mathrm{C}$, and the mixture was stirred vigorously for $90 \mathrm{~min}$. After the mixture was washed and dried, the expansible graphite was obtained. Weighed $2 \mathrm{~g}$ of expansible was put graphite into a beaker, and then the expansible graphite was mixed with concentrated $\mathrm{H}_{2} \mathrm{SO}_{4}$ and $\mathrm{H}_{2} \mathrm{O}_{2}$ solution (volume ratio $10: 1.25$ ) again, and the obtained mixture was also stirred vigorously at $45^{\circ} \mathrm{C}$ for $90 \mathrm{~min}$. After the mixture was washed and dried and calcined at $900^{\circ} \mathrm{C}$ for $15 \mathrm{~s}$ in a muffle furnace, the preparation of MEG samples was accomplished.

2.3. Characterization. The morphology of MEG samples was studied by the field emission scanning electron microscopy (FE-SEM) of S4800. The crystal structure of the samples was determined by the X-ray powder diffractometer (XRD) of D/MAX-rB, which was radiated by $\mathrm{Cu} \mathrm{K} \alpha$ with the pipe pressure of $40 \mathrm{mV}$, the wavelength $(\lambda)$ is $1.54056 \AA$, and the diffraction angle is in the range of $10^{\circ}-80^{\circ}$. The chemical functional groups in the samples were analyzed by the Fourier transformation-infrared spectroscope (FT-IR, EQUINOX55). The $\mathrm{N}_{2}$ adsorption-desorption isotherms and pore size distribution plots were measured by NOVA4000e automatic physical adsorption apparatus, and the measurement was performed at $77 \mathrm{~K}$, the outgas temperature was $250^{\circ} \mathrm{C}$, and the $\mathrm{BJH}$ modeling was used for the pore size determination. Moreover, the thermogravimetric analysis and differential thermal analysis (TG-DTA) curves of the samples were carried out by CRY-2P and WRT-3P analyzer. The atmosphere set during the analysis was argon, and the heating rate was $10^{\circ} \mathrm{C} / \mathrm{min}$.

2.4. Adsorptive Property. A certain amount of seawater and some kind of industrial oils were added into the $200 \mathrm{~mL}$ beaker to simulate the spill oil on the sea. $m \mathrm{~g}$ of $\mathrm{MEG}$ samples was immersed into the liquid mixture, and then MEG samples that absorbed oil and seawater mixture was put on the funnel covered with filter screen (mass $m_{0}, \mathrm{~g}$ ) until the MEG samples have reached the saturation adsorption amount and weighed MEG samples with filter screen (mass $m_{1}, \mathrm{~g}$ ) at that time. The sorption capacity (mass $m_{2}, \mathrm{~g} / \mathrm{g}$ ) of the MEG samples can be calculated by the following formula:

$$
m_{2}=\frac{m_{1}-m_{0}-m}{m}
$$

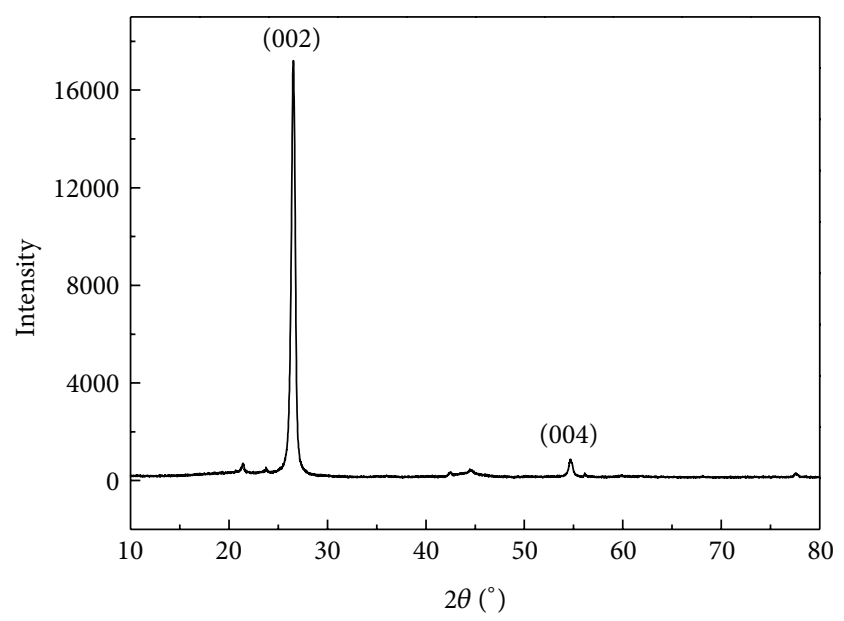

FIGURE 2: XRD pattern of the MEG samples.

\section{Results and Discussion}

3.1. FE-SEM Analysis. Figure 1 shows FE-SEM images of the MEG samples. The morphology of the MEG samples is worm-like as shown in Figure 1(a), and there are a lot of Vtype pores that can also be observed on the surface. These $\mathrm{V}$-type pores with dimension from several dozens of $\mu \mathrm{m}$ to several hundreds of $\mu \mathrm{m}$ are the I level pores, the willow leaftype pores with dimension from several $\mu \mathrm{m}$ to several dozens of $\mu \mathrm{m}$ as shown in Figure 1(b) are ascribed to the II level pores. The pores with dimension from $0.1 \mu \mathrm{m}$ to several $\mu \mathrm{m}$ as seen from Figure 1(c) come from the up and down on the pore walls of the II level pores and are assigned to the III level pores in the MEG samples. It is the particular loose and porous structures that would provide MEG samples with good adsorption property for the macromolecular compounds.

3.2. XRD Pattern. XRD pattern of the MEG is shown in Figure 2. There are two obvious characteristic diffraction peaks located at $2 \theta$ equal to $26.4^{\circ}$ and $54.9^{\circ}$, which corresponded to the (002) and (004) crystal planes, respectively. Crystal phase composition of MEG samples is identified as graphite- $2 \mathrm{H}$ phase according to the standard card of PDF number 41-1487. Thus, it can be inferred that the MEG samples still maintain the crystal structure of natural graphite itself [28], and it also belongs to the graphite crystal. 


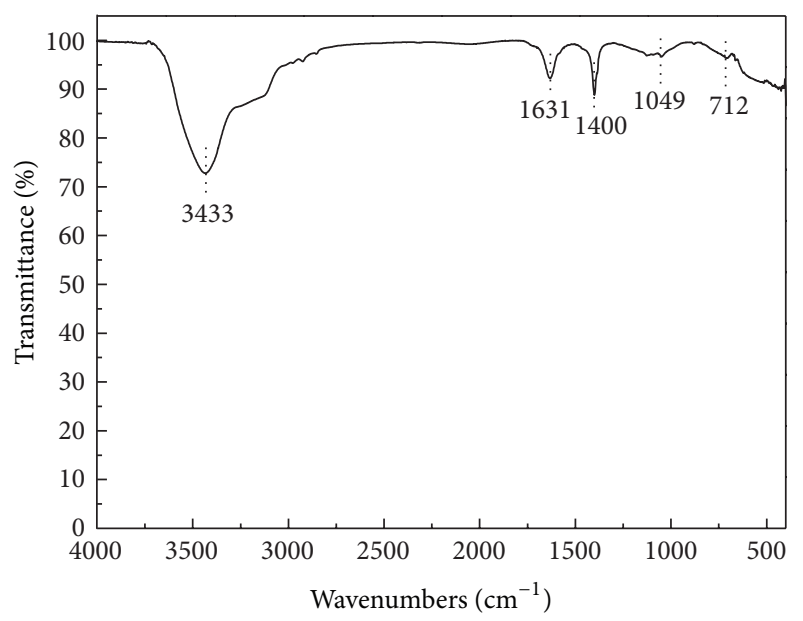

Figure 3: FT-IR spectra of the MEG samples.

3.3. FT-IR Spectra. Figure 3 displays FT-IR spectra of the MEG. The peaks at $3433 \mathrm{~cm}^{-1}$ and $1631 \mathrm{~cm}^{-1}$ are described as stretching vibration absorption peak and deformation vibration absorption peak from water molecules, respectively. They may be derived of adsorbed water from MEG samples and potassium bromide crystal used for pressing pieces and the surface hydroxyl group. The strong peak at $1400 \mathrm{~cm}^{-1}$ is considered the absorption of the methylene fat hydrocarbon from graphitic carbon skeleton. A weak absorption peak at $1049 \mathrm{~cm}^{-1}$ belongs to stretching vibration of C-O-C. The weaker peak at $712 \mathrm{~cm}^{-1}$ corresponds to the absorption of $\mathrm{SO}_{4}{ }^{2-}$, and this may be related to inadequate expansion of modified expandable graphite under heat treatment. The results indicate that a large number of intercalator groups basically disappear after high temperature expansion, and MEG samples can be assigned to nonpolar materials.

3.4. $\mathrm{N}_{2}$ Physical Adsorption Analysis. $\mathrm{N}_{2}$ adsorption-desorption isotherms and pore size distribution plots of the MEG are illustrated in Figure 4. The adsorption-desorption isotherms correspond to the typical type II isotherms (IUPAC, 1985), suggesting the existence of macropores and showing an unobvious hysteresis between adsorption and desorption isotherms.

As shown in Figure 4, there is a small fraction of mesopores in the MEG samples, and the pore diameter is from $2 \mathrm{~nm}$ to $7 \mathrm{~nm}$. These pores with nanometer scale within $100 \mathrm{~nm}$ are attributed to the III level pores of the MEG. Combining with FE-SEM analysis results, the present work divides the pores of MEG into three levels, and it is in agreement with reports [2931 in the literature. In addition, according to the $\mathrm{N}_{2}$ physical adsorption analysis results, the BET specific surface area of the MEG samples is $26 \mathrm{~m}^{2} / \mathrm{g}$, and the pore volume of the MEG samples is $0.069 \mathrm{~cm}^{3} / \mathrm{g}$ by the $\mathrm{BJH}$ modeling.

3.5. TG-DTA Analysis. Figure 5 describes TG-DTA curves of modified expandable graphite. As shown in Figure 5, there is an endothermic peak at $60^{\circ} \mathrm{C}$, and the corresponding mass loss appears in the TG curve, which inferred that some amo-

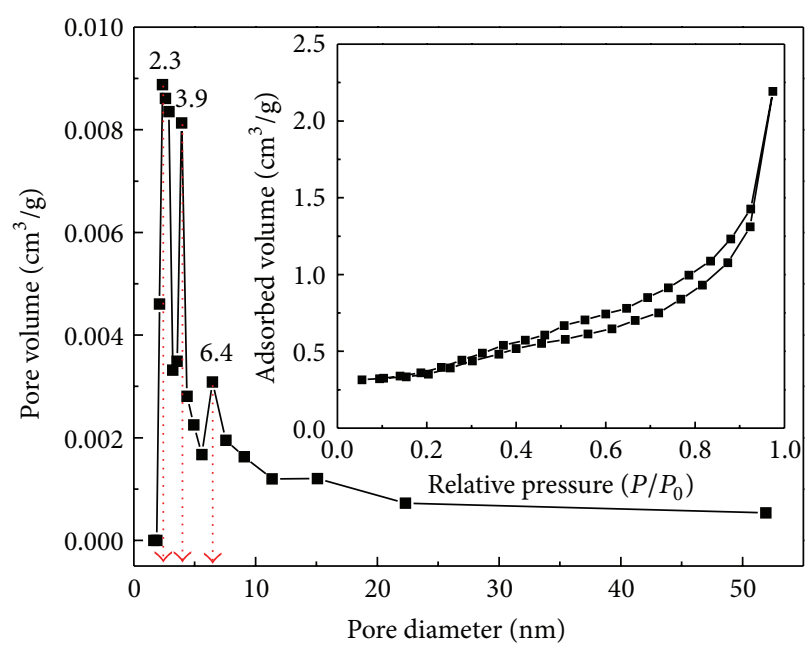

FIGURE 4: $\mathrm{N}_{2}$ adsorption-desorption isotherms and pore size distribution plots of the MEG samples.

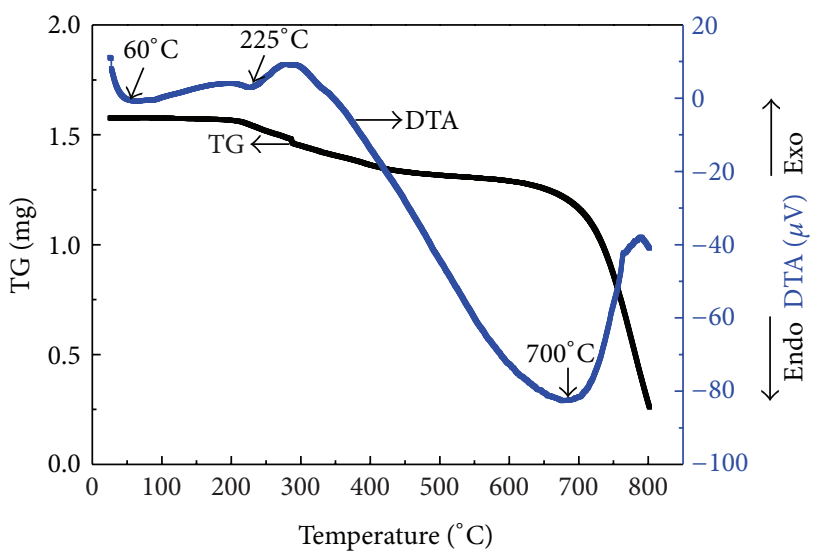

FIgURE 5: TG-DTA curves of MEG precursors.

unt of absorbed water in the samples has been evaporated. Another endothermic peak appears at $225^{\circ} \mathrm{C}$ in the DTA curve, which is attributed to the dehydration of bound water. There is a broad and strong endothermic peak at $700^{\circ} \mathrm{C}$ in the DTA curve, and there is obvious mass loss in the TG curve accordingly. This could be ascribed to the decomposition of $\mathrm{H}_{2} \mathrm{SO}_{4}$-GICs (graphite intercalation compounds) and the burn of graphite, so some $\mathrm{S}-\mathrm{O}$ and $\mathrm{CO}_{x}$ species diffuse out of graphite gallery. The results show that the onset expansion temperature of modified expandable graphite should be scheduled at $700^{\circ} \mathrm{C}$ by using muffle furnace.

\subsection{Adsorptive Property}

3.6.1. Influence of Expanded Volume on Adsorptive Property of the MEG. The maximum sorption capacity of MEG with different expanded volume for kerosene, crude oil, and gear oil is shown in Figure 6. For the same kind of oil, the maximum sorption capacity of MEG increases gradually with the increase of the expanded volume. When the expanded volume of MEG varies between $100 \mathrm{~mL} / \mathrm{g}, 150 \mathrm{~mL} / \mathrm{g}, 190 \mathrm{~mL} / \mathrm{g}$, $250 \mathrm{~mL} / \mathrm{g}$, and $320 \mathrm{~mL} / \mathrm{g}$, the maximum sorption capacities 
TABLE 1: The effect of oil viscosity on sorption capacity of the MEG.

\begin{tabular}{|c|c|c|c|c|c|c|}
\hline Kinds & Gasoline & Kerosene & Diesel oil & Machine oil & Crude oil & Gear oil \\
\hline Viscosity $(\mathrm{Pa} \cdot \mathrm{s})$ & 0.001 & 0.002 & 0.008 & 0.156 & 0.626 & 1.407 \\
\hline Oil absorption (g/g) & 43.25 & 47.657 & 50.879 & 55.128 & 65.537 & 84.681 \\
\hline
\end{tabular}

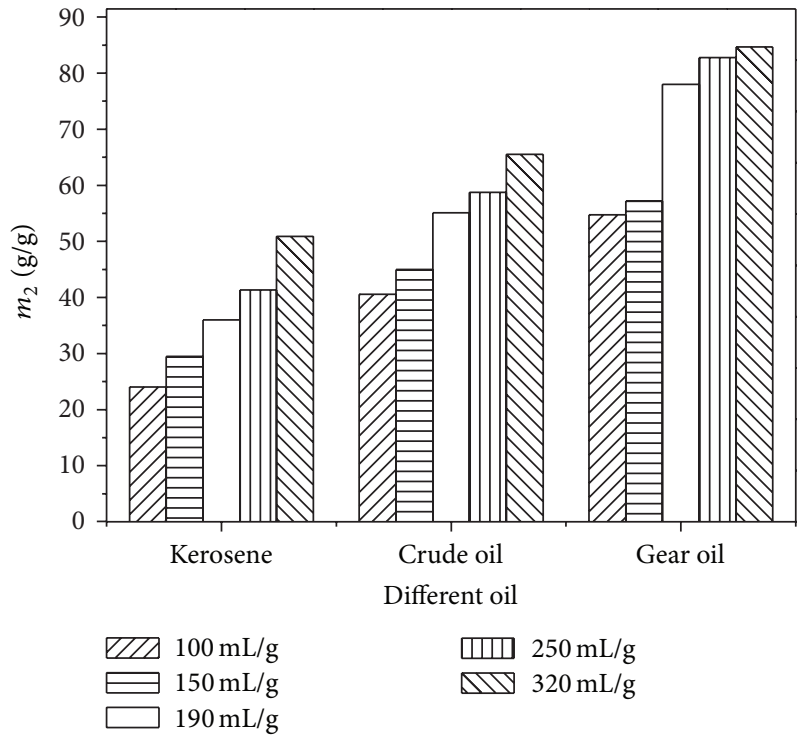

FIGURE 6: The effect of expanded volume on sorption capacity of the MEG samples.

for gear oil are $54.741 \mathrm{~g} / \mathrm{g}, 57.192 \mathrm{~g} / \mathrm{g}, 78.004 \mathrm{~g} / \mathrm{g}, 82.802 \mathrm{~g} / \mathrm{g}$, and $84.681 \mathrm{~g} / \mathrm{g}$, respectively. Moreover, for the same expanded volume, the maximum sorption capacities arrange in the order of gear oil $>$ crude oil $>$ kerosene. When the expanded volume of MEG is $320 \mathrm{~mL} / \mathrm{g}$, the maximum sorption capacities of MEG samples are $50.879 \mathrm{~g} / \mathrm{g}, 65.537 \mathrm{~g} / \mathrm{g}$, and $84.681 \mathrm{~g} / \mathrm{g}$ for kerosene, crude oil and gear oil, respectively. The reasons are as follows: the I level V-type pores make the main contributions to the formation of MEG intertwining space, and the II level willow leaf-type pores constitute a unique internal storage space. So the synergy between the I level pores and the II level pores provides MEG samples with outstanding adsorptivity for several industrial oils [32]. Moreover, the number of the I and II level pores increases with expanded volume increase. So that with the expanded volume increasing, the sorption capacity of MEG samples for oils also increases obviously. The maximum sorption capacity of MEG samples for gear oil is up to $84.681 \mathrm{~g} / \mathrm{g}$.

3.6.2. Influence of Oil Viscosity on Adsorptive Property of the $M E G$. The effect of oil viscosity on sorption capacity of the MEG is listed in Table 1 . The results show that the oil viscosity has a great influence on the sorption capacity of MEG, and the maximum sorption capacity of MEG increases gradually with the increase of the oil viscosity for the same expanded volume. For the low viscosity oil, such as gasoline, kerosene and diesel oil, the maximum sorption capacities of MEG are $43.25 \mathrm{~g} / \mathrm{g}$, $47.657 \mathrm{~g} / \mathrm{g}$ and $50.879 \mathrm{~g} / \mathrm{g}$, respectively. For the high viscosity machine oil and crude oil, the maximum sorption capacities of MEG are $55.128 \mathrm{~g} / \mathrm{g}$ and $65.537 \mathrm{~g} / \mathrm{g}$, respectively. And for the highest viscosity gear oil, the maximum sorption capacity of MEG can be up to $84.681 \mathrm{~g} / \mathrm{g}$. The main reason probably is that the higher viscosity oil has the higher glutinosity and density, and lower liquidity. In other words, high viscosity will be beneficial to the adhesion of MEG and oils.

\section{Conclusions}

To expand and develop the expanded volume of EG and MEG samples were prepared by the strong acid treatment modification. According to above characterization and experiment results, the MEG samples have high graphite crystallinity. The pores of MEG samples can be divided into three levels by FE-SEM. All of the functional groups of MEG samples are nonpolar. The expansion temperature of modified expansible graphite starts at about $700^{\circ} \mathrm{C}$. The sorption capacity of MEG increases gradually with the expanded volume and oil viscosity increase. When expanded volume of MEG samples is $320 \mathrm{~mL} / \mathrm{g}$, the maximum sorption capacity is up to $84.681 \mathrm{~g} / \mathrm{g}$ for gear oil with the highest viscosity. It is the property of multipores and worm-like structures that provide the MEG with high sorption capacity, and it will be a kind of promising adsorptive material in the future.

\section{Conflict of Interests}

The authors declare that there is no conflict of interests regarding the publication of this paper.

\section{Acknowledgments}

This work was financially supported by the Science \& Technology Pillar Program of Hebei Province (no. 12276716D) and the Science \& Technology Research Program of Hebei Province (no. ZD20131010).

\section{References}

[1] C.-Y. Guo and C.-Y. Wang, "Study on preparation of activated mesocarbon microbeads/expanded graphite composites for electrical double layer capacitors," Composites Science and Technology, vol. 67, no. 7-8, pp. 1747-1750, 2007.

[2] A. B. Nair, P. Kurian, and R. Joseph, "Effect of expanded graphite on thermal, mechanical and dielectric properties of ethylene-propylene-diene terpolymer/hexa fluoropropylene-vinylidinefluoride dipolymer rubber blends," European Polymer Journal, vol. 49, pp. 247-260, 2013.

[3] X.-J. Yu, J. Wu, Q. Zhao, and X.-W. Cheng, "Preparation and characterization of sulfur-free exfoliated graphite with large exfoliated volume," Materials Letters, vol. 73, pp. 11-13, 2012. 
[4] Z. Ying, X. Lin, Y. Qi, and J. Luo, "Preparation and characterization of low-temperature expandable graphite," Materials Research Bulletin, vol. 43, no. 10, pp. 2677-2686, 2008.

[5] S. T. Kim, J. Ryu, and Y. Kato, "Optimization of magnesium hydroxide composite material mixed with expanded graphite and calcium chloride for chemical heat pumps," Applied Thermal Engineering, vol. 50, pp. 485-490, 2013.

[6] B. Mortazavi, F. Hassouna, A. Laachachi et al., "Experimental and multiscale modeling of thermal conductivity and elastic properties of PLA/expanded graphite polymer nanocomposites," Thermochimica Acta, vol. 552, pp. 106-113, 2013.

[7] X. Yue, H. Wang, S. Wang, F. Zhang, and R. Zhang, "In-plane defects produced by ball-milling of expanded graphite," Journal of Alloys and Compounds, vol. 505, no. 1, pp. 286-290, 2010.

[8] F. Y. Kang, Y. P. Zheng, H. Zhao et al., "Sorption of heavy oils and biomedical liquids into exfoliated graphite-Research in China," New Carbon Materials, vol. 18, no. 3, pp. 161-1173, 2003.

[9] N. Z. Cao, W. C. Shen, S. Z. Wen, and Y. J. Liu, "Application of expanded graphite adsorption material to environmental protection," Environmental Engineering, vol. 14, no. 3, pp. 27-29, 1996.

[10] S. F. Zhao, X. Y. Pang, R. F. Li, H. X. Li, and T. Gao, "Study on the catalysis of expandable in transesterifiction reaction of animal oil," Carbon, vol. 4, pp. 19-22, 2007.

[11] W. Li, C. Han, W. Liu, M. Zhang, and K. Tao, "Expanded graphite applied in the catalytic process as a catalyst support," Catalysis Today, vol. 125, no. 3-4, pp. 278-281, 2007.

[12] I. M. Afanasov, O. I. Lebedev, B. A. Kolozhvary, A. V. Smirnov, and G. van Tendeloo, "Nickel/Carbon composite materials based on expanded graphite," New Carbon Materials, vol. 26, no. 5, pp. 335-340, 2011.

[13] W. Shen, S. Wen, N. Cao et al., "Expanded graphite-a new kind of biomedical material," Carbon, vol. 37, no. 2, pp. 356-358, 1999.

[14] Y. L. Zhong and T. M. Swager, "Enhanced electrochemical expansion of graphite for in situ electrochemical functionalization," Journal of the American Chemical Society, vol. 134, pp. 1789617899, 2012.

[15] L. Yu, Y. H. Zhang, W. S. Tong et al., "Hierarchical composites of conductivity controllable polyaniline layers on the exfoliated graphite for dielectric application," Composites A, vol. 43, pp. 2039-2045, 2012.

[16] G. Katsukis, J. Malig, C. Schulz-Drost, S. Leubner, N. Jux, and D. M. Guldi, "Toward combining graphene and QDs: assembling CdTe QDs to exfoliated graphite and nanographene in water," ACS Nano, vol. 6, no. 3, pp. 1915-1924, 2012.

[17] G. Wang, Q. Sun, Y. Zhang, J. Fan, and L. Ma, "Sorption and regeneration of magnetic exfoliated graphite as a new sorbent for oil pollution," Desalination, vol. 263, no. 1-3, pp. 183-188, 2010.

[18] X. Q. Yue, R. J. Zhang, F. C. Zhang, and L. Q. Wang, "Decomposition of crude oil absorbed into expanded graphite/ $/ \mathrm{TiO}_{2} / \mathrm{NiO}$ composites," Desalination, vol. 252, no. 1-3, pp. 163-166, 2010.

[19] L. Q. Wang, X. N. Yang, X. L. Zhao, R. J. Zhang, and Y. L. Yang, "Preparation and characterization of expanded graphite with ZnO composites," Advanced Materials Research, vol. 197-198, pp. 770-773, 2011.

[20] A. Goshadrou and A. Moheb, "Continuous fixed bed adsorption of C.I. Acid Blue 92 by exfoliated graphite: an experimental and modeling study," Desalination, vol. 269 , no. $1-3$, pp. 170-176, 2011.

[21] P. Krawczyk, "Effect of ozone treatment on properties of expanded graphite," Chemical Engineering Journal, vol. 172, no. 2-3, pp. 1096-1102, 2011.
[22] Q. W. Han, Q. Zhang, T. P. Li, and L. Zhang, "Testing on electricity character of modified expanded graphite," China Material Technology and Equipment, no. 6, pp. 39-41, 2009.

[23] L. X. Sun, Z. G. Cheng, X. B. Zhao, Y. Cheng, M. Fu, and Q. Liu, "Study of the adsorption of formaldehyde on a modified exfoliated graphite," Carbon, no. 4, pp. 36-39, 2007.

[24] Z. Wu, Y. L. Dong, D. Xu, P. Du, and Z. D. Han, "Study on the dispersion of expanded graphite in POE and its influences on the properties of composites," Chemical Engineer, pp. 4-7, 2011.

[25] C. X. Yan, Z. G. Cheng, W. L. Wu, and M. Fu, "Research on decoloring of wastewater containing methyl orange by modified expanded graphite," Journal of Jiangsu Polytechnic University, vol. 22, no. 1, pp. 21-25, 2010.

[26] C. F. Li, X. M. Luo, and B. Hou, "Surface modification and tribological performance of expanded graphite (EG) as lubricating oil additives," Lubrication Engineering, vol. 32, no. 7, pp. 111-113, 2007.

[27] T. Placke, V. Siozios, R. Schmitz et al., "Influence of graphite surface modifications on the ratio of basal plane to "non-basal plane" surface area and on the anode performance in lithium ion batteries," Journal of Power Sources, vol. 200, pp. 83-91, 2012.

[28] Y. H. Peng and S. X. Jiang, "Preparation of expanded graphite by potassium chlorate," Non-Metallic Mines, vol. 35, no. 3, pp. 3840, 2012.

[29] W. C. Shen and N. Z. Cao, "The porous structure and surface chemical state of expanded graphite," in Proceedings of the European Carbon Conference, vol. 18, pp. 348-349, The Royal Society of Chemistry.

[30] M. Inagaki and T. Suwa, "Pore structure analysis of exfoliated graphite using image processing of scanning electron micrographs," Carbon, vol. 39, no. 6, pp. 915-920, 2001.

[31] M. Inagaki, M. Toyoda, F. Y. Kang, Y. P. Zhang, and W. C. Shen, "Pore structure of exfoliated graphite-a report on a joint research project under the scientific cooperation program between NSFC and JSPS," New Carbon Material, vol. 18, pp. 241249, 2003.

[32] H. Zhao, W. Zhou, W. C. Shen, and F. Y. Kang, "Pore structure of exfoliated graphite and its varieties of liquid sorption," Materials Science \& Engineering, vol. 20, no. 2, pp. 153-155, 2002. 

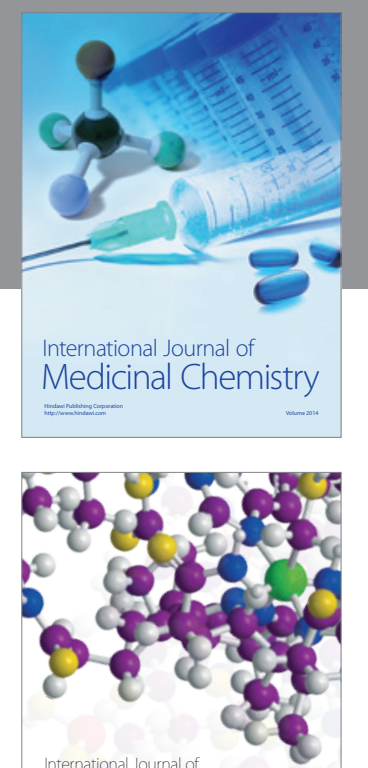

\section{Carbohydrate} Chemistry

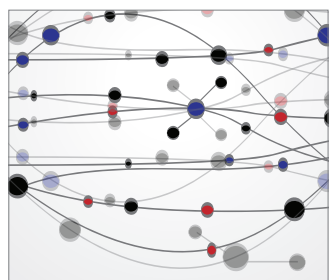

The Scientific World Journal
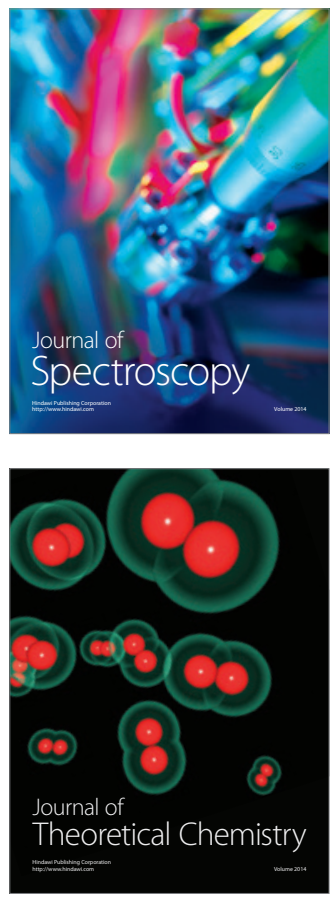
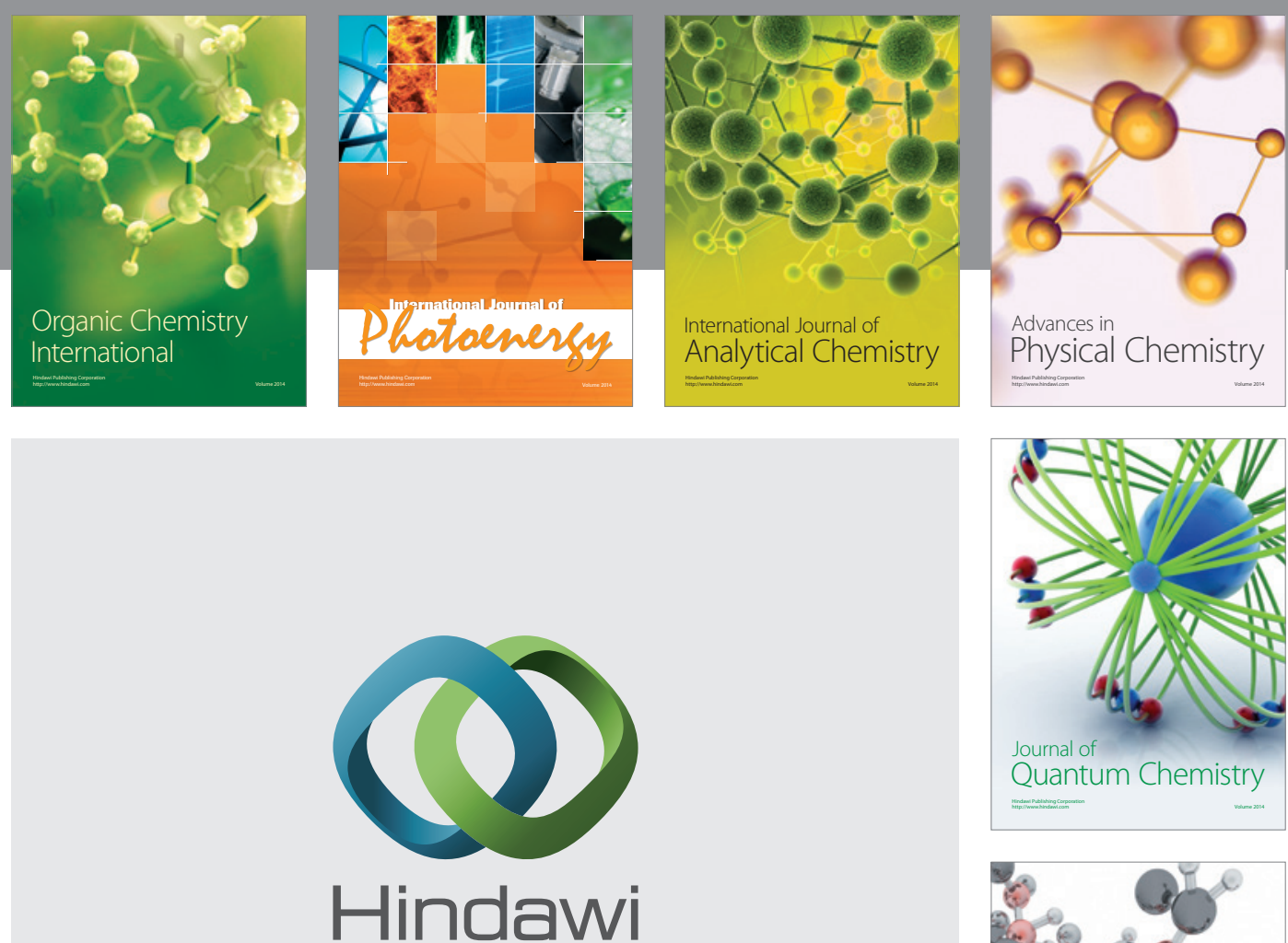

Submit your manuscripts at

http://www.hindawi.com

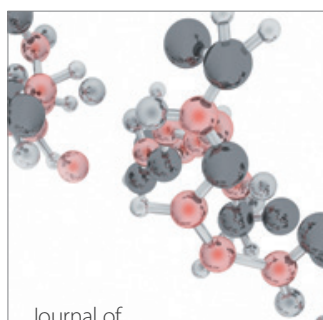

Analytical Methods

in Chemistry

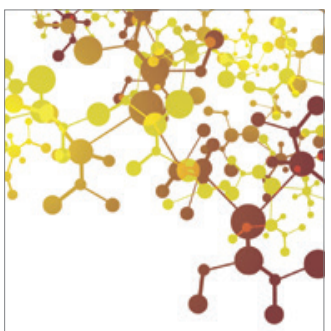

Journal of

Applied Chemistry

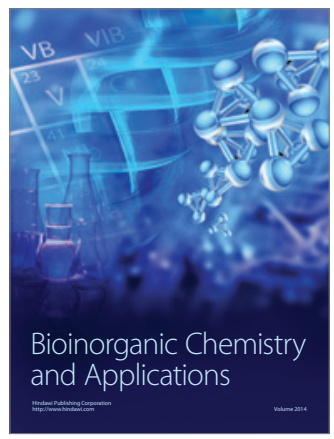

Inorganic Chemistry
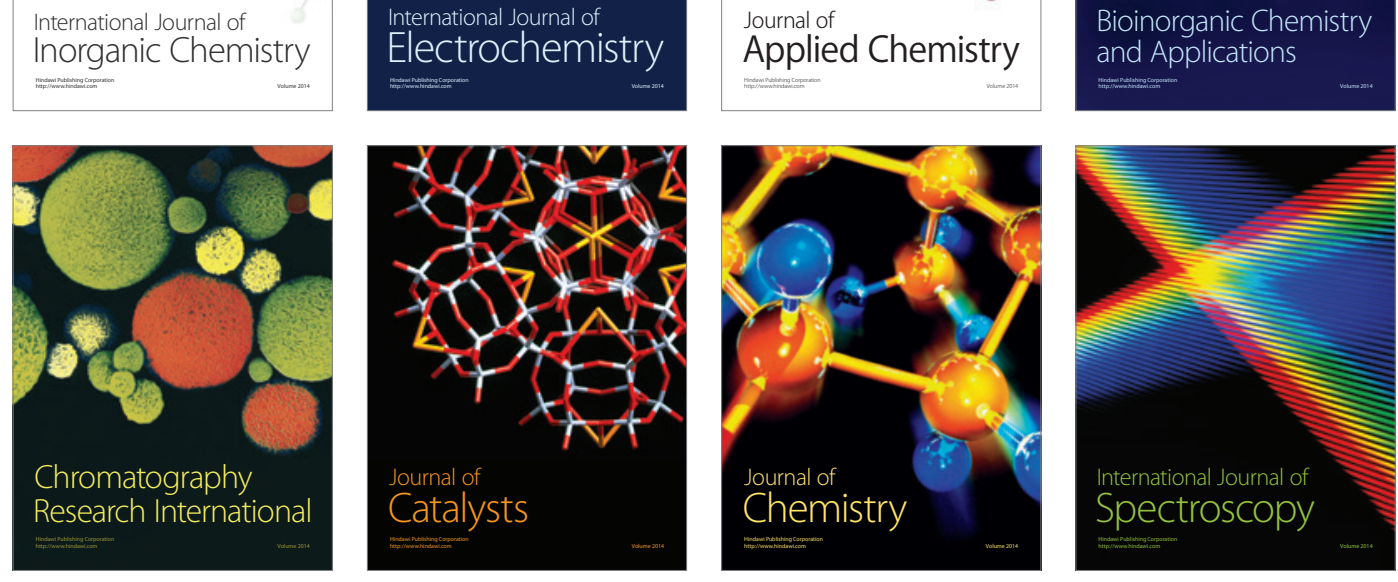